\title{
The Effect of Parent Distraction Coaching Used The Toy on Pain Intensity of 1-5 Year-Old Children during Iv (Intravenous) Insertion
}

\author{
Afrida Ristia ${ }^{1}$, Ai Mardhiyah ${ }^{2}$, Djatnika Setiabudi ${ }^{3}$ \\ ${ }^{1}$ STIKes Cut Nyak Dhien, ${ }^{2}$ Faculty of Nursing, Universitas Padjadjaran, ${ }^{3}$ Central General Hospital of \\ Dr. Hasan Sadikin Bandung \\ Email:afrida_ristia@yahoo.com
}

Submitted: 25-7-2017 Accepted: 7-8-2018 Published: 10-8-2018

\begin{abstract}
Intravenous insertion is the cause of pain that the children most commonly experience when children are being hospitalised. Repeated and insurmountable in early childhood, it will impact trauma to the child, so that pain management is a main priority for nurses. However, nurses have barrier to implement pain management effectively. Therefore, involvement of the parents in pain management was so important. One of the non-pharmacological pain management involving parents is distraction by the parent (Parent Distraction Coaching). The purpose of this research was to examined the difference intensity of pain children from ages 1-5 years old between intervention group and control group during intravenous insertion. This research uses quasi experimental methode by applying the pre-experimental design which is called the intact group comparison. Through the consecutive sampling, the data has been collected from 17 children in each group, both control and intervention groups. Respondents in the intervention group were the children undergoing the intravenous insertion and they were accompanied by their parents' distraction after the parents got the parental distraction coaching, while respondents in the control group were the children undergoing the intravenous insertion in accordance with the hospital procedures but they were not accompanied by their parents' distraction. The assessment of pain intensity was done by using FLACC instruments (Face, Legs, Activity, Cry, and Consolability). The data were analyzed descriptively and tested by using inferential t test-independent where the value of $p<0.05$. From the results of the statistical tests using $t$ test-independent test, the value of $p$ obtained is 0.005 ( $p$ value $<0.05$ ). This value indicates that there is a significant difference between the intensity of pain experienced by children in the control group and in the intervention group during the intravenous insertion. Based on these results, nurses are expected to be aware of the importance of parents or family involvement in reducing the pain experienced by children during intravenous insertion, so that the implementation of pain management in children becomes more effective.
\end{abstract}

Keywords: Distraction, IV (Intravenous) Insertion, pain. 
Afrida Ristia: The Effect of Parent Distraction Coaching Used The Toy on Pain Intensity of 1-5 year-old

\section{Introduction}

The morbidity rate of patients aged $0-21$ in Indonesia was $15.76 \%$ where $27.04 \%$ of that number was patients aged 0-4 (UNICEF, 2012). Lookig at the data, it can be assumed that the number of children being hospitalized will increase. When children are admitted to hospital, they often go through the procedure of IV (intravenous) insertion as a medium for drug intake, fluid and electrolyte fulfillment, and nutrient intake (James, Ghai, Rao, \& Sharma, 2012; Kyle, 2014). The action of the IV insertion is the most common cause of pain that children experience during hospitalization (Cohen, 2008; Kennedy, Luhmann, \& Zempsky, 2008).

Behaviors that indicated more severe pain during IV insertion were shown primarily by 1-5 year-old patients (toddler and preschool children) (Mediani, Mardhiyah, \& Rakhmawati, 2005). Unresolved pain will cause physical effects on children such as rapid and shallow breathing that can lead to hypoxemia, inadequate lung expansion and ineffective cough, an increase in pulse rate, an increase in blood pressure, an increase in stress hormone production (cortisol, adrenaline, catecholamine) that increases metabolism, inhibits healing and decreases immune function and also causes psychological effects such as trauma (Kennedy, Luhmann, and Zempsky, 2008; Twycross, Dowden, \& Bruce, 2009).

Nonpharmacologic pain management should be the primary concern and priority for nurses in order to overcome the pain problems that are experienced by children. However, the implementation of pain management often finds obstacles in the work activities such as the time constraints of nurses (Yulianti, 2010; Yoo, 2011; Koller \& Goldman, 2012). In accordance with the results of Mediani's research (2014), there is a conflict within nurses in Indonesia where the desire of nurses to perform effective pain management can not be done because of the pressure of the role of professional nurses such as the complex conditions in the workplace and the many workloads. To streamline the management of pain on nursing services in children, nurses should establish cooperative relationships with parents or families to provide a better treatment to the children. One of the nonpharmacological pain management involving parents or family is the distraction performed by the parents (Parent Distraction Coaching) (Uman, Chambers, McGrath, \& Kisely, 2008). Parent Distraction Coaching during IV insertion is very important because parents are more sensitive to understand the wishes and behavioral changes of their children when invasive procedures are performed, so that parents can be the main intermediary in the direct care for their children (Bowden, 2010; Commodary, 2010). Parent distraction coaching is very easy and safe for parents to reduce pain experienced by children, where this activity can also increase parental involvement in childcare (Uman et al., 2013; Mc Carthy, 2014). Research which proves the influence of parent distraction coaching on the intensity of pain in children when the invasive procedure is performed is very limited. The results of previous research prove that parent distraction coaching effects on child distress. So in this study, it is necessary to review the effect of parent distraction coaching on pain intensity experienced by children during IV insertion. Based on the preliminary study conducted by researcher in the childcare room at the Central General Hospital of Dr. Hasan Sadikin Bandung in December 2016 on 6 children, the researcher saw that the children were crying constantly, thrashing, and screaming during the intravenous insertion. Nurses also looked anxious when the children showed their excessive reaction to the pain during an IV insertion. Therefore, the children were forced to have their hands and feet firmly fixed, and the parents are not involved in this process. Although parents were present in the room at that time, they were not active in doing the distraction. Repeated exposure of pain may increase the sensitivity to the pain and cause trauma when the children go through the invasive procedures such as IV insertion.

Based on the results of the interviews with several nurses in the nursery room, the nurses said that the main problem in children when the IV insertion is performed is the children cried continuously and even thrashed especially the toddler and preschool children. During the IV insertion procedure, the effort taken by the nurses to 
Afrida Ristia: The Effect of Parent Distraction Coaching Used The Toy on Pain Intensity of 1-5 year-old

reduce the intensity of pain in children is to ask the children to take a deep breath, but this can only be done to the children who already understand the verbal communication. Based on this phenomenon, researcher is interested to examine "The Effect of Parent Distraction Coaching on Pain Intensity of 1-5 Year-Old Children during IV (Intravenous) Insertion at The Central Hospital of Dr. Hasan Sadikin Bandung". This study aims to determine the difference between the intensity of pain experienced by $1-5$ year-old children in the control group and in the intervention group during the IV insertion where the study site is The Central Hospital of Dr. Hasan Sadikin Bandung.

\section{Method}

This research uses quasi experiment method by applying pre-experimental design called intact group comparison. The number of samples which was observed was 34 children who were undergoing IV (intravenous) insertion, in which the intervention group and the control group consisted of 17 children each with the following criteria: a) child with compost mentis, awareness level b) children who are not experiencing interference mentally, c) parents/caretakers of children educated last a minimum of high school. Whereas the criteria ekslusi respondents are: a) child who suffered shock, shortness of breath and need immediate handling (civil defence emergency circumstances), b) child who suffered cancer, c) parents/caretakers of children who experience the disorder of speech, d) parent/caregiver a child who has hearing loss. The intervention group is a group of children who were undergoing the IV insertion and they were accompanied by their parents' distraction, while the control group is a group of children who were undergoing the IV insertion in accordance with the hospital routine and they were not accompanied by their parents' distraction. The sampling technique is consecutive sampling. The assessment of pain intensity was done by using FLACC instruments (Face, Legs, Activity, Cry, and Consolability). Pain measurement at 5 seconds before insertion to 15 seconds while insertion. The data were analyzed descriptively and tested by using inferential $t$ test-independent where the value of $p<0.05$ where the aim is to find out the difference between the intensity of pain experienced by the children in the control and intervention groups when they were undergoing the IV insertion. Respondent's characteristics; the sex of the child, the child's experience, gender parents using statistical test of chi square and the age of the child using the mann-whitney statistical test (distribution data was not normal).

\section{Result}

The research has been conducted on 34 patients aged 1-5 year-old who are undergoing IV (intravenous) insertion in the nursery room where they meet the inclusion criteria of the study. The location of the study was in the Kenanga-1 nursery room at the Central General Hospital of Dr. Hasan Sadikin Bandung. The data that have been collected is analyzed in univariate and bivariate. The results are presented in the following table:

\section{Univariate Analysis}

Univariate analysis was performed to describe respondent's characteristic, intensity of pain in children during the IV insertion, and ability level of parents to perform distraction to their children.

\section{a. Characteristics of Respondents}

Table 1 Characteristics of Respondents in Control and Intervention Group

\begin{tabular}{ccccccccc}
\hline \multicolumn{2}{c}{ Characteristics } & \multicolumn{2}{c}{$\begin{array}{c}\text { Control } \\
\text { Group }(\mathbf{n = 1 7})\end{array}$} & \multicolumn{2}{c}{$\begin{array}{c}\text { Intervention } \\
\text { Group }(\mathbf{n = 1 7 )}\end{array}$} & \multicolumn{2}{c}{ Total } & p Value \\
\cline { 3 - 9 } & & $\mathbf{n}$ & $\mathbf{( \% )}$ & $\mathbf{n}$ & $\mathbf{( \% )}$ & $\mathbf{N}$ & $\mathbf{( \% )}$ & \\
\hline Gender of The & Male & 11 & 64.7 & 10 & 58.8 & 21 & 61.8 & 0.724 \\
Child & Female & 6 & 35.3 & 7 & 41.2 & 13 & 38.2 & \\
IV Insertion & Ever & 14 & 82.4 & 16 & 94.1 & 30 & 88.2 & 0.287 \\
experiences & Never & 3 & 17.6 & 1 & 5.9 & 4 & 11.8 & \\
\hline
\end{tabular}


Afrida Ristia: The Effect of Parent Distraction Coaching Used The Toy on Pain Intensity of 1-5 year-old

\begin{tabular}{ccccccccc}
\hline $\begin{array}{c}\text { Age of the } \\
\text { Child }\end{array}$ & $\begin{array}{c}\text { Toddler } \\
(\mathbf{1}-\mathbf{3})\end{array}$ & $\mathbf{1 2}$ & $\mathbf{7 6 . 5}$ & $\mathbf{1 3}$ & $\mathbf{2 3 . 5}$ & $\mathbf{2 5}$ & $\mathbf{7 3 . 5}$ & $\mathbf{0 . 6 9 7}$ \\
\cline { 2 - 7 } & $\begin{array}{c}\text { Pre- } \\
\text { school } \\
\mathbf{( 4 - 6 )}\end{array}$ & $\mathbf{5}$ & $\mathbf{7 0 . 6}$ & $\mathbf{4}$ & $\mathbf{2 9 . 4}$ & $\mathbf{9}$ & $\mathbf{2 6 . 5}$ \\
\hline $\begin{array}{c}\text { Gender of The } \\
\text { Parents }\end{array}$ & Male & 1 & 5.9 & 1 & 5.9 & 2 & 5.9 & 1.000 \\
\hline
\end{tabular}

Note: value of $p$ used the chi-square statistical test

Table 2 Distribution of Parents' Ability Level in Performing Distraction to Children when They Were Undergoing IV (Intravenous) Insertion

\begin{tabular}{|c|c|c|c|c|c|c|}
\hline \multirow[t]{3}{*}{ Group } & \multicolumn{6}{|c|}{ Ability of Distraction in Phase I } \\
\hline & \multicolumn{2}{|c|}{ Good } & \multicolumn{2}{|c|}{ Enough } & \multicolumn{2}{|c|}{ Less } \\
\hline & $\mathbf{n}$ & $\%$ & $\mathbf{n}$ & $\%$ & $\mathbf{n}$ & $\%$ \\
\hline $\begin{array}{l}\text { Provided with education } \\
\text { (Intervention } n=17 \text { ) }\end{array}$ & 10 & 58.8 & 5 & 29.4 & 2 & 11.8 \\
\hline $\begin{array}{l}\text { Not provided with education } \\
(\text { Control } n=17)\end{array}$ & 3 & 17.6 & 7 & 41.2 & 7 & 41.2 \\
\hline Total & 13 & 38.2 & 12 & 35.3 & 9 & 26.5 \\
\hline Group & \multicolumn{6}{|c|}{ Ability of Distraction in Phase II } \\
\hline & \multicolumn{2}{|c|}{ Good } & \multicolumn{2}{|c|}{ Enough } & \multicolumn{2}{|c|}{ Less } \\
\hline & $\mathbf{n}$ & $\%$ & $\mathbf{n}$ & $\%$ & $\mathbf{n}$ & $\%$ \\
\hline $\begin{array}{l}\text { Provided with education } \\
\text { (Intervention } n=17 \text { ) }\end{array}$ & 10 & 58.8 & 5 & 29.4 & 2 & 11.8 \\
\hline $\begin{array}{l}\text { Not provided with education } \\
(\text { Control } n=17)\end{array}$ & 3 & 17.6 & 6 & 35.3 & 8 & 47.1 \\
\hline Total & 13 & 38.2 & 11 & 32.4 & 10 & 29.4 \\
\hline
\end{tabular}

Table 1 shows that most of the respondents were male $(61.8 \%)$, most of the respondents had IV insertion $(88.2 \%)$, most parents had toddlers $(73.5 \%)$, and most parents or caregivers who accompany their children when their children undergo IV insertion are women $(94.1 \%)$. From the results of homogeneity test of respondents in the control group and intervention group, the researcher got $p$ value $>0.05$ for the characteristics of children's gender, children's experience, age of the children and gender of the parents. It shows that those characteristics in the control and the intervention group are homogeneous.

\section{b. Parent's Ability Level in Parent Distraction Coaching}

Table 2 shows that in the first phase there were $41.2 \%$ of parents or babysitters in the control group (groups not getting education about distractions) who had low ability to perform distractions, and $47.1 \%$ of parents or babysitters in the control group (the noneducated group on distraction) who also had low ability to perform distraction in the second phase. Table 2 also shows that in the first phase there were $58.8 \%$ of parents or babysitters in the intervention group (distraction-educated groups) who had good ability to perform distractions, and there were $58.8 \%$ of parents or babysitters in the group control (the group that gets education about distraction) who has good ability to perform distraction in the second phase. The first phase is 2 minutes before undergoing the infusion, while the second phase begins when the children were stabbed with an intravenous catheter until 2 minutes after they were 
Afrida Ristia: The Effect of Parent Distraction Coaching Used The Toy on Pain Intensity of 1-5 year-old

stabbed with an intravenous catheter.

\section{Bivariate Analysis}

Before the bivariate analysis was done, the researcher performed the data normality test which is the absolute requirement on the parametric test. The normality test was done inferentially by looking at the value of $\mathrm{p}$ in the Shapiro-Wilk test. The normality test results of pain intensity in children when they were undergoing the IV (intravenous) insertion in the control and intervention group showed that the intensity of pain in both groups was normally distributed ( $\mathrm{p}$ value $>0.05$ ). Furthermore, the researcher conducted a t-independent parametric test as illustrated in the following table:

Table 3 Comparison Analysis of Mean Scores of Pain Intensity in Children When They Were Undergoing The IV Insertion in The Control and Intervention Group

\begin{tabular}{ccccc}
\hline Group & N & Mean Score & $\begin{array}{c}\text { Difference of Mean Score } \\
\text { (CI 95\%) }\end{array}$ & p value \\
\hline Control & 17 & 7.12 & & $1.647(0.52-2.76)$ \\
\hline Intervention & 17 & 5.47 & & 0.005 \\
Note: The value of $p$ was the result of unpaired t test &
\end{tabular}

Table 3 shows that the mean score of the pain intensity experienced by children in the control group when they were undergoing the IV insertion was 7.12 and the mean score of pain intensity experienced by children in the intervention group when they were undergoing the IV insertion was 5.47. Based on the further analysis, it was found that there was a significant difference in mean score between the intensity of pain experienced by the children in the control group and the intensity of pain experienced by the children in the intervention group. It was evidenced by the value of $p<0.05(p=0.005$ at $\alpha=0.05)$.

\section{Discussion}

\section{a. Characteristics of Respondents}

Based on the results of this study, it can be described that most respondents were toddlers. Toddlers tend to be more agitated and very active when they feel pain because they are more sensitive to the events around them, but they are easier to calm down so that it helps the parents or babysitters to apply the distraction. This characteristic is supported by the opinion of Cohen (2008) which states that distraction is effective to apply to $<7$ year-old children. Because toddlers are sensitive to their environment, providing them with knowledge and skills is a lot easier (Nurmalitasari, 2016).

Children in the 1-5 year-old category respond faster to the stabbing pain that they will experience, so they feel greater pain when they were undergoing the IV insertion. But in preschool children (3-5 years), children are more easily persuaded and given understanding of the purpose of the IV insertion. As children get older, their cognitive function and coping mechanisms get better. According to Putri, Mardhiyah, and Widianti (2015), preschoolers also depend on the emotional support from their parents or family.

Based on the results of this study, the majority of respondents are boys in either the control group or the intervention group. At the time of the research process, male respondents were given support and counsel by their parents that boys should be strong, not be whiny and be patient, while female respondents always want to be accompanied by their parents or family. This condition is supported by the results of research conducted by Lynch, Kashikar-Zuck, Goldschneider and Jones (2007) that boys have a higher tolerance for pain than girls do. Unlike Mathew (2003), however, the differences in sex are only due to the sensitivity, expression experience, and situational conditions that affect the children in response to pain. Lynch et al. (2007) mentions in his research that girls seek more social support in controlling their pain than boys do.

The results of the analysis of the previous child's experience explained that most of the respondents had undergone IV (intravenous) insertion at Dr. Hasan Sadikin Bandung 
Afrida Ristia: The Effect of Parent Distraction Coaching Used The Toy on Pain Intensity of 1-5 year-old

and other hospitals. Based on the parents' report, it is also known that the children have experiences in IV insertion when they were treated at another hospital. These experiences cause the children to be traumatized by the sight of the nurse and the syringe. This is supported by the opinion of Cohen (2008) that if the management of pain is not done well in the early childhood (golden age) then the pain felt by the children will last long so it can cause trauma and growth disorders and development of children permanently, including neurological development.

The gender of the parents or babysitters who accompanied the children was also discussed in this study. Based on the results of the study, most parents or babysitters who accompany their children when the IV insertion is implemented are the women, ie. their mother or grandmother. The reasons why mothers often accompany their children when the IV insertion is carried out are that the mothers are more skilled, accustomed and often care for their children at home. While the fathers more often work outdoors. However, researcher saw that the ability to distract the children is not limited to the mothers alone but can also be done by the fathers. This is evidenced from a case where the closeness of a child with his father is stronger than that of his mother, because his father is more humorous and calm.

When the IV insertion is implemented, parents or babysitters are adviced to accompany their children so that children do not feel too strange to the surrounding environment. This is evidenced when the children are going through the IV insertion; the children often call on their mothers or fathers' name and have to hug their parents. This situation is supported by the Mercer theory in which the role of parents occurs because of the involvement of children, fathers, and mothers who affect each other (Alligood, 2014). However, Mother is a woman who in most families has a role of a health leader and caregiver. Mother acts as a primary source in providing comfort and assistance when the child is sick (Friedman, 2010). In line with the research conducted by Winarsih (2012), it is known that $81.1 \%$ of the children who are accompanied by their mothers showed better attitude then the children who are accompanied by their father.

\section{b. Level of Ability of Parents to Perform Distraction}

The results showed that some parents or caregivers in the control group had sufficient levels of ability and some had poor levels of ability when they distracted their child at 2 minutes before the child was stabbed with a srynge up to 2 minutes after the IV insertion was completed. In the control group, parents accompany their children according to their habits. When the children were undergoin the IV insertion, the parents are just beside the children without distracting the child properly. Parents look confused, anxious, and sad and sometimes they avoid the situation even they get out of the room as their children are crying, screaming and thrashing because they feel the pain of the needle. They revealed that they did not know how to perform the correct and effective distraction to reduce pain in their children. According to Pillai Riddell et al. (2011) that parental involvement is an important factor in reducing pain in children when the medical procedures are performed. The results of this study also supported by the results of research conducted by McCarthy et al. (2010) that the level of distraction ability given by the mother is very influential on the pain response in children, it means that the higher the distraction level given by the parents, the lower the children's response to the pain when the IV (intravenous) insertion is applied. Therefore, when performing distraction in the children, the parents or babysitters should have characteristics which are appropriate to the characteristics of an effective distraction coach so that the distraction has the effect to reduce pain felt by the children.

In the intervention group, some parents or babysitters have good level of ability to perform distraction to their children before, during, and after the children undergo intravenous insertion. A decrease in the intensity of pain in children in the intervention group may be due to the ability of parents to distract their children. In this group, parents have been educated by researchers for 15 minutes using a video that shows how to distract children exactly when intravenous insertion is performed in children. Video 
Afrida Ristia: The Effect of Parent Distraction Coaching Used The Toy on Pain Intensity of 1-5 year-old

which was shown to the parents or babysitters contain interesting images accompanied by easy-to-understand language so that the parents or babysitters understand how to distract their children easily. This is supported by the results of research by Kapti, Rustina, and Widyatuti (2013) that audiovisual media is a more effective medium in improving mothers' knowledge and attitude in caring for their children. Besides instructional media, Edelman and Mandle (2010) also explain that the appropriate learning strategies to improve one's actions are to demonstrate and practice. When researcher provided education to parents or babysitters and showed the video about distraction, researcher did not involve their children. The goal is that the children will not feel manipulated at the time they undergo intravenous insertion. In contrast to the research conducted by Kleiber et al. (2001), he involves children when parents get education so that children become sensitive and feel manipulated.

Researcher also gave brochures (leaflets) to the parents or babysitters which were associated with the distractions where the goal is to improve their cognitive and social abilities that can help them to understand the information they have received more easily. The parents are advised to do what they have seen in the video. At the time of coaching, parents or babysitters looked very enthusiastic to know about distractions. This is evidenced by their positive questions about the distractions which will be applied on their children.

When researcher gave the education to parents, researcher had sorted out the educational background of the parents or babysitters into the category of higher education so that the information would be accepted and understood more easily by them. The majority of parents or babysitters' educational background is senior high school, but some of them have a Bachelor's or Diploma degree. According to Cutler and Leras-Muney (2006), in general, people with the higher education will have a better learning process because their cognitive skills have been acquired as they study in the school.

The experiences and information received by parents or babysitters greatly affect their ability in performing distractions. Parents or babysitters who bring their children to the hospital for the first time really need more information about the procedures and routines of the hospital so they ask more questions and discussions than those who have more than once brought their children to hospital.

In the intervention group, when the parents or babysitters performed distraction, it was found that there was a difference between their focus at two minutes before the child underwent intravenous insertion (first phase) and when the child was being stuck with a needle (second phase). So, researcher got different scores of parental abilities in these two phases. It is because the parents' attention is greater in the pain experienced by their children and the needle implanted on their children so that the parents or babysitters do not focus on distraction.

\section{c. The difference between mean value of pain intensity in children in control group and intervention group.}

The results of statistical tests show that there is a difference between the mean value of pain intensity in children resulting from intravenous insertion accompanied by the parents' distractions (intervention group) and the mean value of pain intensity in children resulting from intravenous insertion which is not accompanied by parents' distractionss where parents were only accompanying their children as their customs and routines (control groups). The results of this study are in line with the results of research conducted by Sarimin (2012) which shows that the pain felt by the children is reduced when the support of parents or families who have received education and information through brochures are applied to their children. Moreover, the results of the research by McCarthy et al. (2010) show that the mother's distraction ability is very influential to the child's response. It means that the higher the distraction level, the lower the children's pain response to intravenous insertion.

The intensity of pain in children decreases when distraction is performed by parents by using animal piano toys and animated films at 10 minutes before IV (intravenous) insertion is applied so that children are neglected with 
Afrida Ristia: The Effect of Parent Distraction Coaching Used The Toy on Pain Intensity of 1-5 year-old

what they like. Parental distraction coaching is done by combining the senses of sight, hearing and touch like playing with parents accompanied by pleasant words from parents. This will lead to perceptions, pleasant situations and beliefs. Parents or babysitters are part of the family members most trusted by children. Parents are also more patient and understand what children like and want. They are more comfortable when they are invited to play and watch movies with their parents so that the piercing pain stimulus performed on the children can be diverted. It is supported by the opinion of Cohen (2008) which states that, in theory, distraction is more optimal if it involves several modalities such as seeing, listening and touch. In addition, distractions should be given before, during, and after medical procedures are applied.

The results of this study are also supported by the Gate Control theory which states that stimulation of painless nerve fibers such as trust, playful games, and attention can make beta-A neurons release and transmit inhibitor cells (neurotransmitter inhibitors) such as eukafalin and endorphin which serves to regulate the process of defense and inhibition of pain transmission by closing the defense system at the dorsal door of the spinal cord. When the defense door is closed, the pain impulse due to tissue damage is suppressed and not delivered to the brain, while pleasant desending nerve impulses are transmitted to the brain. The impulse coming from the brain affects the asending pain signal from the damaged tissue so that the perceived pain will decrease (Smeltzer \& Bare, 2004; Cohen, 2008). This is supported by the opinion of Cohen (2008) which states that distraction will change the response of nociceptors by activating the internal system of the frontal cortex which can suppress the pain impulse to the brain. According to Olesen, Macoveanu, Tegnér, and Klingberg (2007), the frontal cortex has greater effect on distraction to reduce pain than the parietal cortex has, which is activated when distraction is performed in adults. Children have lower working memory and poorer ability to suppress distraction devices; therefore, distractions are very effective to be applied to children.

The selection of game types used by parents when performing distractions refers to the results of the study of the research literature where the type of distraction that can be used in $\leq 3$ years old children is a game that has the sounds in which the game must be accompanied by pleasant words from the parents. This is applied because children at that age are more easily stimulated by striking colors and loud noises. Unlike children aged $\geq 4$ years, they are able to recognize and understand game tools that use computer screens or mobile phones such as cartoons or animations (Ball, 2008; Bowden, 2010; Taddio et al., 2010). In accordance with the results of research conducted by James et al. (2012), children aged 3-6 years who were given distraction by watching animated cartoons showed that they experienced less pain when they underwent blood sampling through their veins. This is evident from their behavioral responses. According to Brannon et al. (2013), when children focus more on watching cartoons, pain impulses from injury do not flow through the spine and messages do not reach the brain so the child does not feel pain.

The benefits of distraction are more effectively felt by children when the distraction is done by their parents because the children have a very strong inner relationship with their parents or babysitters. Children trust their parents or babysitterss more than others so parents or babysitters can give distractions more easily. Distractions by parents or babysitters can be attributed to theoretical concepts put forward by Kathryn E. Barnard, the Parents Child Interraction (PCI) theory, where the main focus of this theory is the interaction system between parents and children. When parents give distractions, parents are also very sensitive to the needs and cues of their children even though their children are undergoing intravenous insertion. This can be seen from the actions of parents such as responding to children's questions, breastfeeding the children if the needle insertion has not been successful, replace diapers when it was full, and give positive words to the child. Based on these circumstances, the relationship between Parent Distraction Coaching and Parents Child Interraction is when parents give full attention, show patience, and make children feel comfortable. As a result, 
Afrida Ristia: The Effect of Parent Distraction Coaching Used The Toy on Pain Intensity of 1-5 year-old

children's attention can be distracted more easily so that the intensity of pain they feel is reduced. Looking at the results of studies which are demonstrating the effectiveness of parental distraction coaching, the researcher states that parents have a very important role in reducing pain in children when the IV (intravenous) insertion is applied to ther children.

The results of this study are also supported by a study conducted by Sarimin (2012) which explains that there is a difference between the mean value of the intensity of pain in children who are immunized with the support of family or parents and the average value of the intensity of pain in children who are immunized without the support of family or parents. This study, however, is not in accordance with the research by McCarthy et al. (2010) which states that there is no significant difference between the intensity of pain in children who are distracted by their parents and the intensity of pain in children who are not distracted by their parents, but the distraction given by parents is very influential on the distress response of chronically ill children when the intravenous insertion is applied. This may be influenced by topical analgesics given to the children before the intravenous insertion was conducted, so the pain of needle syringe is lower for most children.

Other studies of distractions performed in chronically ill children when the venipuncture procedure was applied were also conducted by Windich-Biermeier, Sjoberg, Dale, Eshelman, and Guzzetta (2007). The results showed that distraction had no significant effect on pain in children during venipuncture, but distraction had a significant effect on the distress experienced by the children. Pain felt by the children is also affected by a topical anesthetic of EMLA given prior to intravenous insertion.

Researchers conclude that parent distraction coaching is done by diverting children's attention to something the child loves, giving words that please children and touching children can reduce the intensity of pain in children. In addition, this activity can minimize separation between child and parent or family, can meet children's play needs, and can reduce trauma in children.
This is consistent with the philosophy of family centered care and traumatic care, such as respecting the integrity of the family, encouraging parent involvement in childcare, preventing and minimizing separation between children and parents or their families and fostering relationships between family, patients and nurses, and prevent pain and bodily injury.

\section{Conclusion}

Based on the results of this study, the researcher concludes that the mean value of the intensity of pain experienced by the children in the control group when intravenous insertion was applied was 7.12 (categorized in the severe pain), while the average value of pain intensity experienced by the children in the intervention group when intravenous insertion was applied was 5.47 (categorized in the moderate pain). So it can be concluded that there is a significant difference between the intensity of pain experienced by the children when intravenous insertion is applied with parents' distraction after the parents were given the coaching and the intensity of pain iexperienced by the children when intravenous insertion is applied without parent's distraction where the parents only accompany their children according to hospital routine ( $\mathrm{p}$ value $<0.05$ ). Expected to nurse can involve parents/ families to accompany the child while insertion intravenous (IV) and conduct education on parents/families through a video about distraction.

\section{References}

Alligood, M.R. (2014). Nursing theorists and their work. Elsevier Health Sciences.

Ball, J., Bindler, R., \& Cowen. (2008). Principle of pediatric nursing (5th Ed.). Caring for children. New Jersey: Pearson Education Inc.

Bowden, V.G.C.S. (2010). Children and their families: The continuum of care (Vol. 1). Philadelphia: Lippincott Williams \& Wilkins. 
Afrida Ristia: The Effect of Parent Distraction Coaching Used The Toy on Pain Intensity of 1-5 year-old

Cohen, L.L. (2008). Behavioral approaches to anxiety and pain management for pediatric venous access. Pediatrics, 122(Supplement 3), S134-S139.

Cutler, D.M., \& Lleras-Muney, A. (2006). Education and health: Evaluating theories and evidence. National Bureau of Economic Research.

James, J., Ghai, S., Rao, K., \& Sharma, N. (2012). Effectiveness of "Animated Cartoons" as a distraction strategy on behavioural response to pain perception among children undergoing venipuncture. Nursing and Midwifery Research Journal, 8(3), 198-207.

Kapti, R.E., Rustina, Y., \& Widyatuti, W. (2013). Efektifitas audiovisual sebagai media penyuluhan kesehatan terhadap peningkatan pengetahuan dan sikap ibu dalam tatalaksana balita dengan diare di dua Rumah Sakit Kota Malang. Jurnal Ilmu Keperawatan, 1(1), 5360.

Kennedy, R.M., Luhmann, J., \& Zempsky, W.T. (2008). Clinical implications of unmanaged needle-insertion pain and distress in children. Pediatrics, 122(Supplement 3), S130-S133.

Kleiber, C., Craft-Rosenberg, M., \& Harper, D.C. (2001). Parents as distraction coaches during IV insertion: A randomized study. Journal of pain and symptom management, 22(4), 851-861.

Kleiber, C., McCarthy, A.M., Hanrahan, K., Myers, L., \& Weathers, N. (2007). Development of the distraction coaching index. Children's Healthcare, 36(3), 219235.

Koller, D., \& Goldman, R.D. (2012). Distraction techniques for children undergoing procedures: A critical review of pediatric research. Journal of Pediatric Nursing, 27(6), 652-681.

Lynch, A.M., Kashikar-Zuck, S., Goldschneider, K.R., \& Jones, B. A. (2007). Sex and age differences in coping styles among children with chronic pain. Journal of pain and symptom management, 33(2), 208216.

McCarthy, A. M., Kleiber, C., Hanrahan, K., Zimmerman, M. B., Westhus, N., dan Allen, S. (2010). Impact of parent-provided distraction on child responses to an IV insertion. Children's Health Care, 39(2), 125-141.

Mediani, H.S., Mardhiyah, A., \& Rakhmawati, W. (2005). Respon nyeri infant dan anak yang mengalami hospitalisasi saat pemasangan infus di RSUD SumedangPain responses of hospitalized infants and children to intravenous cannulation during hospitalization in Sumedang Distric Hospital. Abstrak.

Nurmalitasari, F. (2016). Perkembangan sosial emosi pada anak usia prasekolah. Buletin Psikologi, 23(2), 103-111.

Olesen, P.J., Macoveanu, J., Tegnér, J., \& Klingberg, T. (2007). Brain activity related to working memory and distraction in children and adults. Cerebral Cortex, 17(5), 10471054.

Putri, M.S., Mardhiyah, A., \& Widianti, E. (2015). Gambaran respon anak usia prasekolah dalam menjalani proses transfusi. Jurnal Keperawatan Padjadjaran, 3(3).

Sarimin, D.S. (2012). Efektivitas Paket Dukungan Keluarga (PDK) terhadap respon perilaku nyeri bayi yang dilakukan prosedur imunisasi di RSUP Prof. Dr. R.D. Kandou Manado. Thesis. Fakultas Keperawatan Universitas Indonesia.

Smeltzer, S.C, \& Bare, B.G. (2004). Textbook of surgical medical nursing. Philadhelpia: Lippincott William \& Wilkins.

Taddio, A., Appleton, M., \& Bortulossi, R. (2010). Reducing the pain of childhood vaccination an enhanced clinical practice guidelines. CMA Journal, 182(18), 19891995.

Twycross, A., Dowden, S., \& Bruce, L. 
Afrida Ristia: The Effect of Parent Distraction Coaching Used The Toy on Pain Intensity of 1-5 year-old

(2009). Managing pain in children: A clinical guide. John Wiley \& Sons.

Uman, L.S., Birnie, K.A., Noel, M., Parker, J.A., Chambers, C.T., McGrath, P.J., \& Kisely, S.R. (2013). Psychological interventions for needle related procedural pain and distress in children and adolescents. The Cochrane Library.

Uman, L.S., Chambers, C.T., McGrath, P.J., \& Kisely, S. (2008). A systematic review of randomized controlled trials examining psychological interventions for needle-related procedural pain and distress in children and adolescents: An abbreviated Cochrane review. Journal of pediatric psychology, $33(8), 842-854$.

UNICEF. (2012). Kesehatan Ibu \& Anak.

Windich-Biermeier, A., Sjoberg, I., Dale, J.C., Eshelman, D., \& Guzzetta, C.E. (2007). Effects of distraction on pain, fear, and distress during venous port access and venipuncture in children and adolescents with cancer. Journal of Pediatric Oncology Nursing, 24(1), 8-19. 